\title{
Association of Lhermitte-Duclos and Cowden disease: report of a new case and review of the literature
}

M Vinchon, S Blond, J P Lejeune, I Krivosik, P Fossati, R Assaker, J L Christiaens

\begin{abstract}
Lhermitte-Duclos disease is a rare entity, and its pathological features are unique. Pathological findings are characteristic of the disease, with global hypertrophy of the cerebellum, coarse gyri, and the typical "inverted cortex" pattern. Several associated lesions were noted in many patients with Lhermitte-Duclos disease. It is only recently that an association between Lhermitte-Duclos disease and Cowden disease was reported. Cowden disease, or multiple hamartomas syndrome, is a familial disease associating breast cancer, cutaneomucous tricholemmomas, and various other tumoural and dysplasic conditions. A new case of Lhermitte-Duclos disease associated with Cowden disease is reported. A review of the literature found 72 cases of Lhermitte-Duclos disease; 26 had conditions suggesting Cowden disease and seven were definite cases of Cowden disease. The association of Lhermitte-Duclos disease and Cowden disease is probably underestimated. Cowden disease represents a new form of phakomatosis; Lhermitte-Duclos disease may occur as a sporadic disease, or as part of familial Cowden disease. The possibility of preneoplastic states in Cowden syndrome stresses the importance of a thorough screening when LhermitteDuclos disease is diagnosed.
\end{abstract}

Neurochirurgie

hôpital B, Chr de

Lille, France

$M$ Vinchon

$S$ Blond

J P Lejeune

R Assaker

J L Christiaens

Laboratoire de

Neuropathologie,

hôpital B, Chr de

Lille, France

I Krivosik

Service

d'Endocrinologie,

USN A, Chr de Lille,

France

P Fossati

Correspondence to:

Matthieu Vinchon, service

de Neurochirurgie, Hôpita

B, Chr de Lille, 59037 Lill

cedex, France.

Received 5 April 1993

and in final revised form

2 August 1993.

Accepted 18 August 1993 present clinically with signs and symptoms suggesting a slowly expanding lesion in the posterior fossa. Owing to its growth potential, it has been regarded for a long time as a tumoural disease, despite preserved cytoarchitecture and the lack of mitoses, anaplasia, or angiogenesis. Such names as gangliocytoma, ganglioneuroma, and purkinjeoma should be avoided, as its nature is dysplasic, and not tumoural, and the cells involved are granular and not Purkinje cells.

Many patients with Lhermitte-Duclos disease have a large head, independent of the possible presence of hydrocephalus, and some have a high arched palate. Since the review of the literature by Ambler et $a l,{ }^{6}$ who retrieved 36 cases, a variety of other malformations have been commonly found in association with Lhermitte-Duclos disease, such as hydromyelia, hypertrophy of the olivary nuclei, white matter neuronal heterotopias, leontiasis ossea, ${ }^{7}$ cutaneous angioma, ${ }^{8-10}$ lipoma, ${ }^{11} 12$ or congenital malformation of the extremities. ${ }^{61314}$ Some patients with Lhermitte-Duclos disease also had a tumour, benign or malignant, of the breast, ${ }^{615}$ parotid gland, ${ }^{7}$ colon, ${ }^{6} 16$ thyroid gland, ${ }^{5915-17}$ or brain. ${ }^{918}$ Ambler et al also reported the only familial occurrence of Lhermitte-Duclos disease in the literature.

Cowden disease, or multiple hamartoma disease, is a rare familial disease defined by the association of cutaneous and oral tricholemmomas, with dysmorphic anomalies and a propensity to develop tumours of the skin, breast, thyroid, or gastrointestinal tract. Padberg et al ${ }^{15}$ reported two cases of Lhermitte-Duclos disease in two distinct families, having relatives more or less affected with features of Cowden disease. They postulated that Lhermitte-Duclos disease might be a manifestation of Cowden disease. We report a new case of Lhermitte-Duclos disease associated with Cowden disease. Lhermitte-Duclos disease was the first manifestation, and this case was the subject of a former report. ${ }^{9}$ This patient comes from a large family in which many members have been affected with other conditions probably related to Cowden disease. To clarify the relation between Lhermitte-Duclos disease, and Cowden disease, we reviewed the cases reported in the literature since the first general review of Ambler $e t a l^{6}$ with special attention to associated diseases. 
Figure 1 CT scan, performed in 1980 because of symptoms of raised intracranial pressure, disclosed a round, well delimited, homogeneously enhancing space-occupying lesion. A partial resection was performed.

Pathological examination showed it to be a benign astrocytoma.

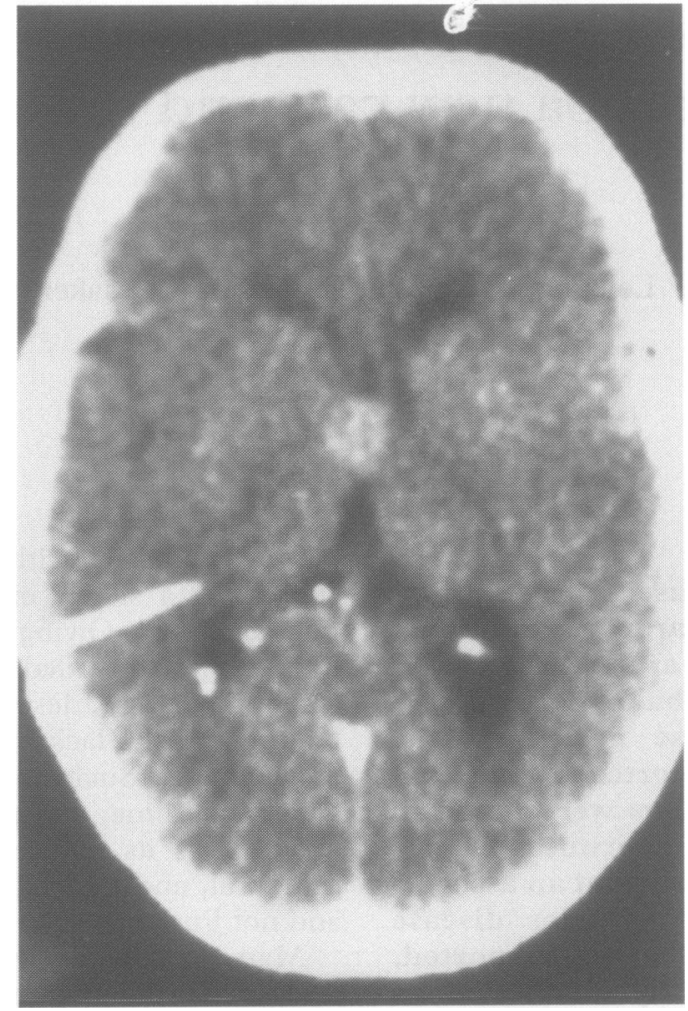

\section{Case report}

The patient was born in 1956 with a weight of $5 \mathrm{~kg}$. She had transient neonatal anoxia, without apparent sequelae. Her mother had diabetes mellitus, and several of her 14 siblings also had macrosomia at birth. The patient had rickets, and walked at 30 months. She was seen for the first time in our department in 1971 , aged 16, for ataxia and symptoms of

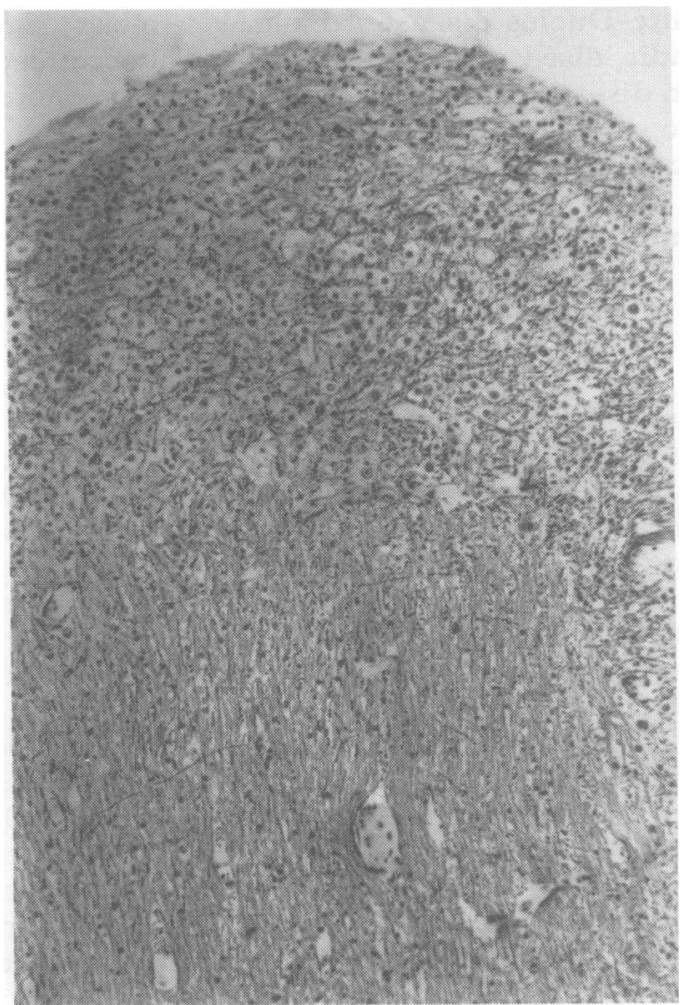

raised intracranial pressure. The investigations failed to confirm the suspected tumour of the posterior fossa, and a provisional diagnosis of aqueduct stenosis was made. The patient underwent ventriculoatrial shunting, with a good relief of symptoms. She had a nodule in her left breast (no pathology available) removed in 1974, aged 18. In 1980, the symptoms of raised intracranial pressure recurred, and a CT scan (fig 1) disclosed a trigonoseptal tumour. She underwent craniotomy, with partial resection of the lesion through a transventricular approach. The tumour was a benign astrocytoma. No further treatment was advised. In 1983, pelvic echography was performed because of metrorrhagia and disclosed an ovarian cyst. She was given hormonal treatment. She had a nodule in her right breast removed in 1984 (no pathology available). In the same year, she was investigated in the department of endocrinology, and a diagnosis of hypothalamic hyperprolactinaemia was made, the origin of which remains unclear. She was treated with bromocriptine. In 1986, her neurological symptoms recurred, with a pronounced gait ataxia. A repeat CT scan showed a hypodense, non-enhancing mass in the posterior fossa. MRI showed a large, illdefined lesion compressing the brainstem. At craniotomy, the occipital bone was noted to be very thin. The cerebellar gyral pattern appeared preserved, albeit firmer than normal, and a tough, whitish tissue was found underneath. It was easily resected, although its limits with the cerebellar peduncle were blurred, so that resection was only partial. Pathological examination (fig 2) showed features characteristic of Lhermitte-Duclos disease. The postoperative course was uneventful, and her gait improved considerably. She then developed a goitre, and underwent subtotal thyroidectomy in 1989. Pathological examination disclosed a microinvasive vesicular carcinoma.

She was seen again in our department in September 1992, There was no neurological deficit, apart from a mildly ataxic gait and a cerebellar tremor in the left arm. She had no major intellectual impairment, with an overall IQ of 92 , verbal IQ of 86 , and memory IQ of 92. Her head circumference was $62 \mathrm{~cm}$. Dermatological examination showed several tricholemmomas over the nose subclavian area, and right elbow. She had a high arched palate, with upper jaw endoclusia. Control MRI (fig 3) showed no change in the posterior fossa and trigonoseptal lesions. A characteristic coarse gyral pattern could be recognised in the cerebellum, especially in the axial view (fig 4). Chromosomal banding showed no karyotypic aberration.

Familial screening was informative (fig 5). The patient's mother, now aged 70 , aside from her diabetes mellitus, was treated medically for a diffuse goitre. A goitre was also found in three of the patient's eight sisters. The patient's four maternal uncles all died of a gastric cancer and her elder brother also died of a cancer, allegedly located "in the region of 
Figure 3 MRI, September 1992, sagittal view: persistence of a large cerebellar mass with no coarse gyral pattern is identified in the upper vermis (large straight arrow). Note the vertical cerebelli (small arrows), in evolution of the disease.

The curved arrow points at the trough in the corpus callosum caused by the transventricular approach to the trigonoseptal tumour. contrast uptake. The orientation of the tentorium relation to the protracted

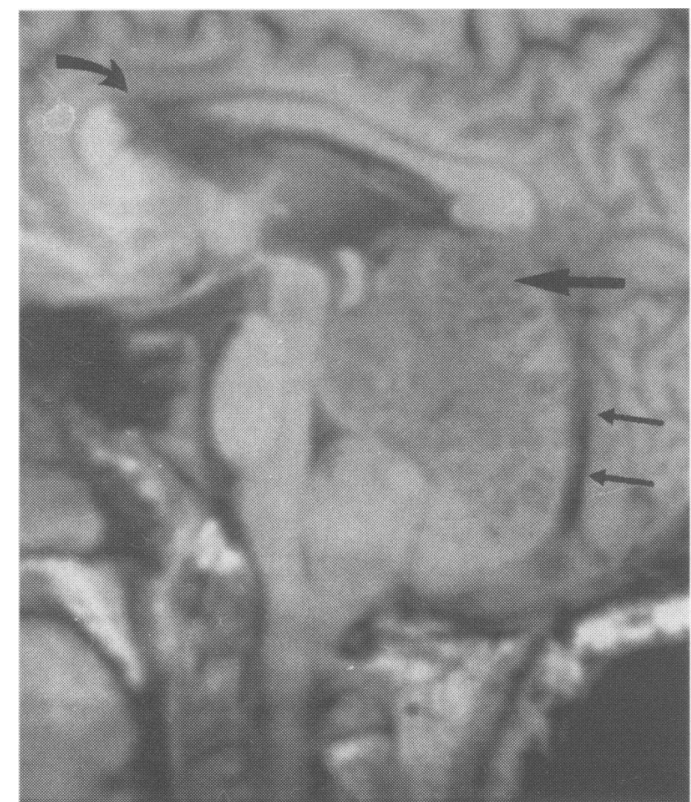

the neck". One of the patient's nephews was shunted for hydrocephalus of unknown origin.

\section{Review of the literature and discussion}

We reviewed the cases of Lhermitte-Duclos disease published in the literature, including the cases collected by Ambler et al ${ }^{6}$ and more recent ones. More than 76 cases have been reported. Of these, only 71 had the minimal clinical data (age, sex, clinical presentation) needed for our study. The data regarding associated dysmorphic or tumoural conditions

Figure 4 MRI,

September 1992 axial view: the brainstem is displaced by a swollen cerebellar cortex, with no cistern visible. The

enlarged cerebellar folia are easily seen (arrows). Right temporal artifacts are

related to the shunt valve.

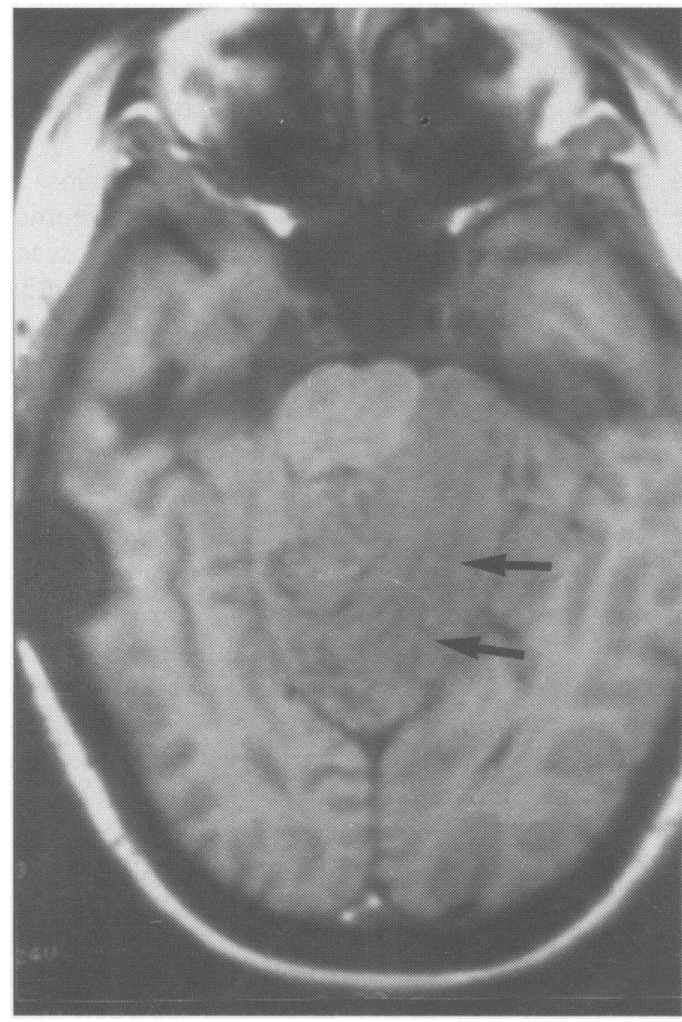

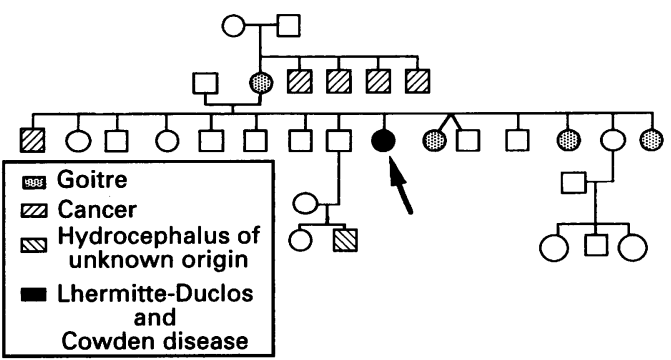

Figure 5 Family tree of the patient (arrow). Her mother and three of her sisters had goitre. Her four uncles and her elder brother died of a cancer. One nephew has hydrocephalus of unknown origin.

in the patients, or their relatives, were especially researched.

We retrieved 72 cases, ${ }^{1-47} 32$ females and 29 males, with a mean age of 33.7 (range 1 to 74, SD 14) years.

Clinical presentation consisted most often of symptoms of raised intracranial pressure and ataxia. In rare cases, other signs were present, such as impairment of cranial nerves, ${ }^{1}$ long tract dysfunction, ${ }^{19}$ or orthostatic hypotension..$^{1636}$

The duration of symptoms before diagnosis was reported in 28 cases. The mean was 46.0 months, with broad variations: in nine cases, it was shorter than one year; in six, it was one to two years; in six, it was two to four years. In eight cases, it was longer than five years, with a duration of more than 10 years in five cases.

Treatment was generally based on surgery alone. The extent of resection may be difficult to define, in the absence of tumoural limits, and because of the multifocal nature of the disease. ${ }^{5}$ Medical treatment, based on antioedema drugs may have some effect, as reported by Sonier et $a l^{41}$ but these authors did not report the outcome after six months. Recurrence is not rare among long-term survivors: seven had local progression of the disease years after the first operation, and three had to be reoperated on.

The outcome was not as favourable in many cases as the term "benign cerebellar hypertrophy" would suggest. Twenty eight patients died, with 25 patients dying of the tumour itself or after surgery. A high mortality was found mainly in the oldest cases, however: 10 cases reported before 1978 were alive, and 23 were dead, $v$ five dead and 27 alive after 1978 (no outcome reported in six cases). Most recent cases made a good postoperative recovery, so that associated diseases might occur later. Two patients died of metastatic carcinoma in relation to Cowden disease, ${ }^{67}$ and one of status epilepticus of unknown origin. ${ }^{34}$

\section{ASSOCIATED LESIONS}

No other disease was reported in the patients or their relatives in 42 cases. In the remaining 29 , noteworthy findings were reported.

\section{Involvement of the CNS}

Megalencephaly should be distinguished from macrocephaly secondary to obstructive hydrocephalus. In live patients, CT scan or MRI 
allow such distinction. In necropsy series, brain weight is a good indicator. Normal brain weight for adults is 1300 to $1500 \mathrm{~g}$ in males, 1200 to $1400 \mathrm{~g}$ in females. ${ }^{6}$ Brain weight was reported in 12 cases: it was more than $1700 \mathrm{~g}$ in 11 cases. Head perimeter was reported in 13 cases: it was at or above $60 \mathrm{~cm}$ in all 13 cases. Macrocephaly was considered to be present in 10 patients, with no figure reported by the authors. In total, out of 41 patients for which this information was provided, 35 patients had macrocephaly, and only six had a normal head size.

Intellectual impairment was found in six patients. ${ }^{691530}$ Although it had often been known for a long time before diagnosis, it may be difficult to assess the real impact a posterior fossa tumour may have on intellectual development. All cases had macrocephaly, and three of these had Cowden disease.

Epilepsy was found in five cases, ${ }^{6} 153134$ preceding other symptoms in three cases. ${ }^{634}$

Other involvements of the CNS were reported. In the earliest publications, necropsy examination often disclosed CNS malformations, such as syringomyelia, ${ }^{6}$ hypertrophy of olivary nuclei, ${ }^{1843}$ and white matter neuronal heterotopia. ${ }^{14}$ Nowadays, MRI can disclose discrete, subclinical alterations in live patients, such as gliosis in the centrum semiovale, ${ }^{15}$ syringomyelia, ${ }^{17}$ or anomalies of venous drainage in the cerebellum and cerebral hemispheres. ${ }^{10}$ Padberg et $a l^{15}$ assumed that epilepsy was secondary to these white matter lesions.

\section{Other lesions}

Tumoural, malformative, or dysplasic disease of a remarkable diversity, may be associated with Lhermitte-Duclos disease:

Lesions of the skin and subcutaneous tissue have been found-namely, tricholemmomas, ${ }^{910-121547}$ cutaneous angioma, ${ }^{8-10}$ or cavernous hemangioma, ${ }^{8}$ lipoma, ${ }^{11}$ angiolipoma, ${ }^{12}$ leontiasis ossea, ${ }^{7}$ café-au-lait spots. ${ }^{6} 1117$

Dysmorphic anomalies of the extremities may occur-namely, large feet, ${ }^{13}$ large hands, ${ }^{6}$ a large thumb, ${ }^{14}$ polyctylia. ${ }^{6}$ Enlargement of hands and feet was also reported in a patient's brother, both being affected with Cowden disease. ${ }^{47}$

Tumours may be associated with Lhermitte-Duclos disease: goitre or carcinoma of the thyroid, ${ }^{5915-1747}$ breast cancer, ${ }^{6,9,15,23}$ polyps of the colon, ${ }^{16}$ of the duodenum, ${ }^{6}$ cancer of the kidney, ${ }^{44}$ carcinoma of the parotid, ${ }^{7}$ of the uterus, ${ }^{7}$ or glial tumours: glioblastoma ${ }^{18}$ or low grade astrocytoma. ${ }^{9}$

Miscellaneous diseases include carotidcavernous fistula, lymphoid hyperplasia in the lung, ${ }^{12}$ cavernous angiomas of the liver, of the ovary, ${ }^{47}$ ovarian cyst, ${ }^{910}$ and recurrent retinal detachment. ${ }^{11}$

\section{FAMILIAL INCIDENCE}

In 56 cases, no significant pathological association was reported in the patient's relatives.

Lhermitte-Duclos disease occurred in two related patients (mother and son) in a single occurrence. ${ }^{6}$ The mother had characteristic features of Cowden disease, and died of metastatic breast carcinoma. The son had epilepsy, and both had macrocephaly and mental dullness.

Macrocephaly was reported in relatives in eight occurrences, 5152327304547 four of them being considered as cases of Cowden disease.

Epilepsy was found in relatives on two occasions, ${ }^{12} 15$ both in association with Cowden disease. Mental retardation was found in three cases, ${ }^{615}$ and psychosis in one. ${ }^{47}$

In his study of 15 subjects from two families of patients with Lhermitte-Duclos disease, Padberg et $a l^{15}$ found macrocephaly in eight siblings, epilepsy in two, cerebellar symptoms in six. On MRI, anomalies were found in three siblings, gliosis in two, and developmental anomalies of the cerebellum in one. Cutaneous angiomas were reported in two of the cases of Padberg et al. ${ }^{15}$ Tumours of the thyroid (goitre or carcinoma) were found in four more cases, ${ }^{915} 17$ tumours of the breast in one, ${ }^{15}$ lipoma in one, ${ }^{47}$ and stomach cancer in the present report.

\section{COWDEN DISEASE}

This familial disease was first reported in 1963 by Lloyd and Dennis, ${ }^{48}$ who named it from the first patient described. Several women in her family were affected with breast cancer, and many siblings had thyroid adenomas, a high arched palate, mental retardation, or skin tumours. Two patients had cerebellar tremor but none underwent neuroradiological investigations. Buccal and cutaneous tricholemmomas are considered constant in Cowden disease, but may be overlooked if not specifically researched. Macrocephalia is a common feature in Cowden disease, as well as a high arched palate, malformations of the extremities, vascular malformations, and lipomas. ${ }^{49}$ We have seen that all these features could also be found in Lhermitte-Duclos disease.

Lhermitte-Duclos disease associated with Cowden disease seems to be a rare condition. ${ }^{49}$ The first case was reported in $1981 .{ }^{12}$ Including retrospective cases of LhermitteDuclos disease not initially recognised as Cowden disease, nine cases have been reported to date. ${ }^{6910-121547}$ In all but one of these cases, relatives were affected with one or more features of Cowden disease. This prompted Padberg et $a l^{15}$ to state that Lhermitte-Duclos disease and Cowden disease are "a single phakomatosis". In our review however, many cases of Lhermitte-Duclos disease seemed isolated, although we cannot be sure that Cowden disease was not overlooked. Familial occurrence of Lhermitte-Duclos disease was reported only once, and both patients had features of Cowden disease. ${ }^{6}$ On the other hand, some patients with known Cowden disease may have asymptomatic Lhermitte-Duclos disease. In the absence of systematic neuroradiological screening in patients with Cowden disease, the real incidence of Lhermitte-Duclos disease in Cowden disease is as yet unknown. 
NOSOLOGICAL QUESTIONS

Our study suggests that Lhermitte-Duclos disease may be either a sporadic, isolated disease, or occur in association with Cowden disease, in a context of familial disease. The last could be renamed Lhermitte-Duclos-Cowden disease. Familial occurrence of LhermitteDuclos disease was reported only once in the literature, in probable association with Cowden disease. ${ }^{6}$

Owing to the fact that tricholemmoma is classically considered a prerequisite for the diagnosis of Cowden disease, only a small number of cases of Lhermitte-Duclos disease meet the criteria for this diagnosis. Tricholemmomas, however, may be very discrete and be taken for trivial warts, so that they are easily overlooked. Every patient with Lhermitte-Duclos disease should be screened for the presence of other elements of Cowden disease. In the absence of tricholemmoma, however, the existence of other prominent features of this syndrome such as breast or thyroid cancer in the patients or their relatives should be enough to raise the question of Cowden disease. On the other hand, patients with Cowden disease should have clinical and neuroradiological investigations to exclude Lhermitte-Duclos disease.

Our review of the literature stresses the close relation between Lhermitte-DuclosCowden Disease, and other phakomatoses: dysplasic lesions of the cerebral or cerebellar cortex are found in tuberous sclerosis. ${ }^{50}$ Malformations or tumours of vascular origin are characteristic of Rendu-Osler, Von Hippel-Lindau, and Sturge-Weber diseases; cutaneous neurofibromas and café-au-lait spots are characteristic of neurofibromatosis; visceral tumours and dysplasic lesions may be found in several phakomatoses, including neurofibromatosis and von Hippel-Lindau's disease. Our opinion is that Cowden disease is a phakomatosis, and Lhermitte-Duclos disease may be either sporadic, or part of this phakomatosis.

\section{CONCLUSION}

Our report shows how important a life-long follow up and a thorough personal and familial screening are for patients with LhermitteDuclos disease. A review of the literature shows that the number of patients having Lhermitte-Duclos disease associated with Cowden disease is underestimated. Lhermitte-Duclos disease should be researched with MRI in patients with Cowden disease, and patients with Lhermitte-Duclos disease and their families should be investigated for Cowden disease, because some lesions are preneoplastic states.

In a number of cases however, no other lesion could be found in the patient or his relatives. We think that these are genuine sporadic cases, as opposed to cases associated with Cowden disease. Lhermitte-Duclos disease seems to share the same kind of relation with Cowden disease that cerebellar hemangioblastoma has with Von HippelLindau disease.
1 Lhermitte J, Duclos P. Sur un ganglioneurome diffus du cortex du cervelet. Bull Assoc Fr Et Cancer 1920;9: 99-107.

2 Shiurba RA, Gessaga EC, Eng LF, Sternberger LA, Sternberger NH, Urich H. Lhermitte-Duclos disease. Acta Neuropathol (Berl) 1988;75:474-80.

3 Yachnis AT, Trojanovski JQ, Memmo M, Schlaepfer WW. Expression of neurofilament proteins in the hypertrophic granule cells of Lhermitte-Duclos disease. f Neuropath Exp Neurol 1988;47:206-16

4 Roski RA, Roessmann U, Spetzler RF, Kaufman B, Nulsen F. Clinical and pathological study of dysplastic gangliocytoma. $\mathcal{F}$ Neurosurg 1981;55:318-21.

5 Beuche W, Wickbold J, Friede RL. Lhermitte-Duclos disease-its minimal lesions in microscope data and CT findings. Clin Neuropathol 1983;2:163-70.

6 Ambler M, Pogacar S, Sidman R. Lhermitte-Duclos disease (granule cell hypertrophy of the cerebellum). Pathological analysis of the first familial cases. Pathological analysis of the first famil

I Neuropathol Exp Neurol 1969;28:622-47.
7 Schmidt MB. Uber halbsetitigen Riesenwuchs des Schädels und seine Beziehung zu Leontiasis und Ostitis fibrosa. Beitr Anat Physiol Pathol Ther Ohres Nase Halses 1926;23:594-600.

8 Duncan D, Snodgrass SR. Diffuse hypertrophy of the cerebellar cortex (myelinated neurocytoma). Arch Neurol Psychiatry 1943;50:677-84.

9 Lejeune JP, Blond S, Dupard T, Combelles G, Delandsheer JM, Christiaens JL. Maladie de LhermitteDuclos: à propos d'une observation. Neurochirurgie 1987;33:408-11.

10 Williams DW, Elster AD, Ginsberg LE, Stanton C. Recurrent Lhermitte-Duclos disease: report of two cases and association with Cowden's disease. Am $\mathcal{F}$ Neuroradiol 1992;13:287-90.

11 Marano SR, Johnson PC, Spetzler RF. Recurrent Lhermitte-Duclos disease in a child. $f$ Neurosurg 1988; 69:599-603.

12 Russel JR, O'Brien M, Welles RS. Cowden's disease. Br $\mathcal{F}$ Dermatol 1981;105 suppl 19:57-8.

13 Gessaga EC. Lhermitte-Duclos disease (diffuse hypertrophy of the cerebellum) Report of two cases. Neurosurg Rev 1980;3:151-8.

14 Ostertag B. Handbuch der speziellen pathologischen Anatomie und Histologie. Berlin: Springer 1956;4:553.

15 Padberg GW, Schot JDL, Vielvoye GJ, Bots G Th, deBeer FC. Lhermitte-Duclos disease and Cowden disease: a single phakomatosis. Ann Neurol 1991;29: disease:

16 Fischer $\mathbb{W}$, Busch K Th. Gangliozytome: klinische und morphologische Betrachtungen. Zentralbl Neurochir 1963;23:286-311.

17 Sabin HI, Lidov HG, Kendall BE, Symon L. LhermitteDuclos disease (dysplastic gangliocytoma): a case report with CT and MRI. Acta Neurochir (Wien) 1988; 93:149-53

18 Carbone F, Brihaye J, Drochmans P. Spongioblastome parièto-occipital et gangliocytome dysplasique du cervelet chez le même malade. Acta Neurol Psychiatrice Belg 1955;55:568-80.

19 Ashley DG, Chi-Shing Z, Chandrasoma PT, Segall HD. Lhermitte-Duclos disease: CT and MR findings. f Comput Assist Tomogr 1990;14:984-7.

20 Brown WR, Angelo JN, Kelly DL. Lhermitte-Duclos disease: case report with computerized tomographic scan. Neurosurgery 1980;6:189-91.

21 Carter JE, Merren MD, Swann KD. Preoperative diagnosis of Lhermitte-Duclos disease by magnetic resonance imaging. F Neurosurg 1989;70:135-7.

22 Di Lorenzo N, Lunardi P, Fortuna A. Granulomolecular hypertrophy of the cerebellum (Lhermitte-Duclos disease). I Neurosurg 1984;60:644-6.

23 Faillot T, Sichez JP, Brault JL, et al. Lhermitte-Duclos disease (dysplastic gangliocytoma of the cerebellum): report of a case and review of the literature. Acta Neurochir (Wien) 1990;105:44-69.

24 Ferrer I, Isamat F, Acebes J. A Golgi and electron microscopy of a dysplastic gangliocytoma of the cerebellum. Acta Neuropathol (Berl) 1979;47:163-5.

25 Fiol RE, Grant T, Gandara JD, Longo R. Benign hypertrophy of the cerebellar cortex. F Neuropath Exp Neurol trophy of the cerebellar

26 Harff EG, Vinken PJ. A case of diffuse cerebellar hypertrophy. Acta Neuropathol (Berl) 1966;6:106-11.

27 Leech RW, Christopherson LA, Gilbertson RL. Dysplastic gangliocytoma (Lhermitte-Duclos disease) of the cerebellum. ₹ Neurosurg 1977;47:609-12.

28 Milbouw G, Born JD, Collignon J, Hans P, Reznik M, Bonnal J. Clinical and radiological aspects of dysplastic gangliocytoma (Lhermitte-Duclos disease): a report of two cases with review of the literature. Neurosurgery 1988;22:124-8.

29 Pritchett PS, King TI. Dysplastic gangliocytoma of the cerebellum - an ultrastructural study. Acta Neuropathol (Berl) 1978;42:1-5.

30 Reeder RF, Saunders RL, Fratkin JD, Cromwell LD. Magnetic resonace imaging in the diagnosis and treatment of Lhermitte-Duclos disease. Neurosurgery ment of Lhern

31 Reznik M, Schoenen J. Lhermitte-Duclos disease. Acta Neurochir (Wien) 1983;59:88-94.

32 Rilliet B, Mori Y. Gangliocytome dysplasique du cervelet. Schweizer Arch Neurol Neurochir Psychiatrie 1979;124: 13-27. 
33 Roach ES, Williams DP, Laster DW. Magnetic resonance imaging in tuberous sclerosis. Arch Neurol 1987;44: 301-3.

34 Roessmann U, Wongmongkolrit T. Dysplastic gangliocytoma of the cerebellum in a newborn. $f$ Neurosurg 1984;60:845-7.

35 Rousseaux M, Combelles G, Krivosik Y, Christiaens JL. Maladie de Lhermitte-Duclos: hypertrophie granulomoléculaire du cervelet. Neurochirurgie 1987;33:232-5.

36 Ruchoux MM, Gray F, Gherardi R, Schaeffer A, Comoy J, Poirier J. Orthostatic hypotension from a cerebellar gangliocytoma (Lhermitte-Duclos disease). $\mathcal{f}$ Neurosurg 1986;65:245-52.

37 Ruchoux MM. La maladie de Lhermitte-Duclos [thesis]. Tours, France: Université François Rabelais de Tours, Faculté de Médecine, 1985.

38 Schafer JA, Berg BO, Norman D. Cerebellar calcification in tuberous sclerosis. Arch Neurol 1975;32:642-3.

39 Shanley DJ, Vassallo CJ. Atypical presentation of Lhermitte-Duclos disease: preoperative diagnosis with MRI. Neuroradiology 1992;34:103-4.

40 Smith RR, Grossman RI, Goldberg HI, Hackney DB, Bilaniuk LT, Zimmerman RA. MR imaging of Lhermitte-Duclos disease: a case report. $\mathrm{Am} f$ 89;10:187-9.

41 Sonier C-B, Feve J-R, deKersaint-Gilly A, Ruchoux MM, Rymer R, Auffray E. Lhermitte-Duclos disease: a rare case of intracranial hypertension in adults. $\mathcal{F}$ Neuroradiol 1992;19:133-8.

42 Stapleton SR, Wilkins PR, Bell BA. Recurrent dysplastic cerebellar gangliocytoma (Lhermitte-Duclos disease) presenting with subaract

43 Spiegel E. Hyperplasia des Kleinhirns. Beitr Pathol Anat 1920;67:539-48.

44 Hallervorden J. Über die Hamartome (Ganglioneurome) des Kleinhirns. Dtsch Ztschr Nervenheilk 1959;179:531-63.

45 Maccombe WBA. A case of Lhermitte-Duclos disease. Clin Exp Neurol 1983;19:120-2.

46 Hair LS, Symmans F, Powers JM, Carmel P. Immunohistochemistry and proliferative activity in Lhermitte-Duclos disease. Acta Neuropathol (Berl) 1992;84:570-3.

47 King MA, Coyne TJ, Spearritt DJ, Boyle RS. LhermitteDuclos disease and Cowden disease: a third case. Ann Neurol 1992;32:112-3.

48 Lloyd KM, Dennis M. Cowden's disease. Ann Intern Med 1963;58:136-42.

49 Starink M. Cowden's disease: analysis of fourteen new cases. $\mathcal{F}$ Am Acad Dermatol 1984;11:1127-41.

50 deRecondo J, Haguenau M. Pathology of phakomatoses. In: Vinken PJ, Bruyn GW, eds. Handbook of clinical Neurology. Vol 14. Amsterdam: North Holland publishing company, 1972:19-100. 